\title{
A "Geografia Urbana" como disciplina: uma abordagem possível
}

Ana Fani Alessandri Carlos ${ }^{1}$

Resumo: O texto apresenta uma possibilidade de construção teórico-metodológica para o desenvolvimento da disciplina Geografia Urbana, ministrada no Departamento de Geografia da FFLCH, no âmbito do curso de Graduação. Os conteúdos apóiam-se no movimento de constituição de uma geografia crítica que coloca a noção de produção do espaço no centro do debate sobre o urbano e a sociedade urbana como momento necessário de compreensão do mundo moderno, a partir de sua dimensão sócio-espacial. Podemos pressupor que todo ato de realização da vida humana tem um parâmetro e uma realidade espaço-temporal, o que significa que as atividades desenvolvem-se por um determinado período de tempo num lugar específico que caracteriza e dá conteúdo à ação humana. O número especial desta revista nos faz refletir sobre o modo como vimos "pensando e fazendo Geografia" ao longo do tempo neste Departamento, seja através da pesquisa, seja através do ensino e da formação dos alunos, como desdobramento e superação da Geografia que nos foi legada.

Palavras-chave: geografia urbana; espaço urbano; urbano; cidade; vida cotidiana.

\section{The "Urban Geography" as discipline: a possible approach}

Abstract: This work presents a possibility of theoretical-methodological construction for the development of the Urban Geography course, ministered at the Geography Department in $F F L C H$, under the graduation course. The contents are supported by the constitution movement of a critical geography that places the notion of production of space in the center of the debate about the urban and the urban society, as necessary moments of the contemporary world comprehension, starting form its socio-spatial dimension. We assume that every act of human life realization has a spatiotemporal parameter and reality, which means that the activities are developed by a determined period of time in a specific place that features and gives content to human action. This journal special issue makes us reflect on the way we have been "thinking and making Geography" over time in this Department, whether through research, either through education and formation of students as unfolding and overcoming the Geography that we inherited.

Key-words: urban geography; urban space; urban; city; everyday life.

\section{PREÂMBULO}

Os anos 70 apresentam uma guinada importante na produção do conhecimento geográfico no Brasil, a partir de intenso debate sobre os rumos da disciplina, o qual foi influenciado por questionamentos vindos do exterior. É o momento em que o espaço deixa de ser sinônimo de localização e o homem deixa de ser o habitante para ser o sujeito da produção do mundo,

\footnotetext{
${ }^{1}$ Graduação e Licenciatura em Geografia pela Universidade de São Paulo, mestrado, doutorado e livre-docência em Geografia Humana pela Universidade de São Paulo. Professora Titular do Departamento de Geografia da Faculdade de Filosofia, Letras e Ciências Humanas da Universidade de São Paulo. E-mail: anafanic@usp.br
} 
o que implicou na necessidade de trazer para a Geografia a complexidade da vida social. Por outro lado, constitui-se também uma forte reação frente à ciência usada ora para alimentar e justificar a prática do Estado, ora para atender às necessidades da reprodução econômica. Assim, como o outro da Geografia, preocupada com sua aplicação e submetida à lógica do Estado que faz tabula rasa da prática sócio-espacial esvaziando e autonomizando os espaços-tempos da vida social, uma nova perspectiva se abria apoiada no pensamento crítico e no método dialético.

Respaldado pelas possibilidades abertas pelo materialismo dialético, como condição da produção de um conhecimento geográfico do mundo em que vivemos, um grupo de pesquisadores (Amélia Luisa Damiani, Ana Fani Alessandri Carlos, Margarida Maria de Andrade, Odette de Lima Seabra) membros do LABUR (Laboratório de Geografia Urbana) e da rede "La somme et le reste" (cuja revista de mesmo nome é coordenada na França por Armand Azemberg) vai se constituindo, no Departamento de Geografia da FFLCH-USP, nos anos 70/80. O exercício da liberdade que aí vigora, contra qualquer tipo de intolerância ou preconceito teórico, permitiu, ao longo do tempo, a consolidação de uma Geografia fundada no pensamento marxista-lefevriano, que se realiza através das pesquisas dos envolvidos tanto individuais quanto de orientação no LABUR e no Programa de Pós-graduação surgindo como possibilidade de fundamentação de cursos ministrados.

O que apresentamos a seguir é a construção de uma disciplina de graduação, respaldada por esta orientação teórico-metodológica, ministrada no D.G., expondo o modo como vimos "pensando e fazendo Geografia" neste Departamento, produto de nossas pesquisas na área de Geografia Urbana.

\section{INTRODUÇÃO}

A realidade urbana encontra-se em constante processo de transformação que ocorre hoje num lapso de tempo cada vez menor. Esse ritmo marca a modernidade e coloca um conjunto de desafios no sentido de compreender os conteúdos atuais da problemática urbana.

Atualmente o fenômeno urbano se estende sobre parte significativa do globo, anunciando sua tendência à mundialização. Assim, não sem conflitos, o urbano vai penetrando os espaços, generalizando-se a partir de pontos centrais no território. Isto ocorre porque as 
condições do capitalismo não são estáticas, ele se desenvolve realizando virtualidades: o espaço mundial e a sociedade urbana. Essa produção revela a essência do que poderíamos chamar de "novo" no mundo moderno. As mudanças se impõem à análise, portanto pode-se pensar que existe, ao longo da constituição do conhecimento geográfico, um movimento constante de superação e de busca de novos caminhos teórico- metodológicos o que pressupõe a elaboração de noções e conceitos articulada à prática social como totalidade que se define dinamicamente.

Deste modo, o desafio posto no horizonte para a construção do programa desta disciplina é desvendar os novos conteúdos da realidade social através de sua dimensão espacial sem fragmentar a totalidade dos processos constitutivos e reveladores do mundo urbano. 0 movimento da totalidade (teórica e prática) obriga-nos a deslocar a centralidade da análise do espaço - como localização da atividade humana - para a produção do espaço - como criação civilizatória, social e histórica. Esta perspectiva obriga o distanciamento do debate do campo da epistemologia para aquele que contempla a relação teoria-prática como construção da dialética constante entre o plano da vida (realizando-se enquanto prática sócio-espacial em suas condições objetivas) e aquele do conhecimento (a geografia que pretende produzir uma compreensão sobre a realidade, no âmbito das ciências humanas). Portanto o espaço como conceito e como prática aponta para o movimento de sua produção/reprodução como momento central da compreensão do mundo moderno.

Deste modo é possível estabelecer, inicialmente, que a realidade atual em suas profundas metamorfoses coloca a necessidade de desvendamento do seu conteúdo e sentido como produto da realização do capitalismo no plano mundial, um momento da reprodução da sociedade, saída da história da industrialização, que permitiu - com o desenvolvimento do mundo da mercadoria, apoiado no desenvolvimento das comunicações, na expansão da informação - a generalização do valor de troca, e com ela a redefinição das relações entre os lugares, pelas metamorfoses da divisão do trabalho no seio da sociedade. A extensão do capitalismo no espaço, ele próprio tornado mercadoria neste processo, faz da produção do espaço, a condição e o produto da reprodução social como elemento definidor dos conteúdos da prática sócio-espacial, modificando as relações espaço-tempo da vida social. Nesse contexto, o processo de urbanização, longe de significar o mero crescimento da cidade ou a extensão do tecido urbano, revela um conteúdo que se insere num processo mais amplo; aquele do desenvolvimento do modo de produção capitalista como 
fundamento da constituição de uma "sociedade urbana" apresentando um processo profundo de transformação nas formas e conteúdos da produção da cidade, bem como da existência humana na cidade como existência prática real e concreta dos cidadãos.O conteúdo do mundo moderno passa, assim, pelo desvendamento da cidade - no que ela se tornou - passa, ainda, pelo debate sobre a sociedade urbana, pela discussão de um projeto capaz de orientar as transformação da cidade construída sob a lógica da acumulação capitalista em suas contradições. É nesta medida que à transformação do espaço se alia a necessidade da compreensão desse movimento/momento da realidade pela Geografia. Assim, a transformação do espaço urbano exige a transformação da Geografia.

Algumas considerações se fazem necessárias para pensar a orientação da disciplina: a) a provisoriedade do conhecimento decorrente da própria dinâmica da realidade que determina o trabalho de pesquisa - não existe uma verdade absoluta; b) a existência de várias possibilidades teórico-metodológicas abertas à elaboração do pensamento geográfico sobre a acidade e o urbano o que envolve o debate entre autores de diversas tendências não existe um caminho verdadeiro e um falso; c) o fato de que tanto a cidade quanto o urbano são objetos de análise de várias disciplinas e campos do conhecimento; d) a noção de que a crítica, que se impõe como necessidade intrínseca da produção do conhecimento, tende a se esterilizar no mundo moderno, e precisa, portanto, ser revalorizada e revitalizada. Do ponto de vista da Geografia Urbana podemos pensar o urbano como o modo pelo qual a reprodução do espaço se realiza na contemporaneidade, como realidade e como possibilidade. Nesta direção, coloca-se a necessidade a) de desvendar a realidade urbana que aparece e vem sendo apresentada como caótica num mundo em crise que, em sua dimensão sócio-espacial, desafia a compreensão dos geógrafos frente às profundas mudanças no espaço e no tempo; b) de pensar os novos conteúdos da urbanização superando as análises que a restringem a uma questão quantitativa referente ao aumento do número dos habitantes nas cidades e aglomerações urbanas; c) de pensar a pratica sócioespacial como momento explicativo que revela a profunda indissociabilidade entre produção do ser humano e a produção do espaço.

Nesta perspectiva, o processo de produção do espaço (como categoria central direcionadora da construção de um raciocínio sobre a cidade e o urbano) tem como pressuposto a natureza, e, neste sentido, aponta a atividade humana como produtora e transformadora, movida por vontade e disposição, acasos e determinações. Nesse processo, transforma-se a 
natureza em mundo, uma realidade, essencialmente, social. Essa luta na construção do mundo é a condição constitutiva do espaço urbano.

O mundo como produção, no movimento das relações sociais, supera, hoje, as fronteiras e, encontra-se cada vez mais distante de uma natureza primeira. Se por um lado o homem produz, em vários momentos históricos, as condições necessárias à produção/reprodução da vida, por outro ele o faz produzindo a si mesmo como sujeito ativo. Essa atividade produz um mundo e um conhecimento sobre esse mundo. Mas se a realidade é uma construção objetiva, material, ao mesmo tempo, a sociedade, para além de um processo de objetivação, contempla um processo de subjetivação na medida em que ela adquire consciência prática desta mesma realidade. Deste modo, o processo de subjetivação não se refere ao plano fechado do indivíduo, deslocado de uma prática sócio-espacial produtora de uma consciência coletiva (o vivido e o percebido inter-relacionados e não separados em sua pura subjetividade ou presa às particularidades do espaço).

Assim, através da Geografia, é possível construir um pensamento capaz de revelar o movimento que vai da localização dos homens e de suas atividades na superfície da terra à produção do espaço como momento da produção da vida em todas as suas dimensões (numa articulação dos planos econômico, político e social) como movimento da reprodução da sociedade ao longo da história. Nessa direção, a análise do espaço urbano apresenta-se como reveladora das relações sociais: sua produção e o caminho de sua reprodução.

O pressuposto do qual partimos para a construção da disciplina, nesta perspectiva teórica, é o de compreender a produção do espaço urbano como condição/meio e produto da reprodução social, processo que revela, hoje, a profunda contradição entre a produção social do espaço e sua apropriação privada, indicando o espaço-tempo onde se confrontam as necessidades da acumulação do capital em conflito com as necessidades da reprodução da vida em seus significados mais profundos. A centralidade da noção de produção aponta àquela da reprodução do espaço e permite considerar o movimento que vai da "diferenciação espacial" como análise das particularidades dos lugares, ao estudo da prática sócio-espacial como conteúdo do lugar revelando a condição objetiva da existência humana em suas alienações e focando a fragmentação do espaço localizada no universo mercantil, e a segregação como produto da implosão/explosão da cidade no movimento do processo de urbanização contemporânea (advinda do processo de industrialização) apontando a propriedade privada da riqueza como definidora dos modos de acesso à cidade. Nesta 
condição, a propriedade paira abstratamente sobre a sociedade, redefinindo os modos de uso dos lugares, delimitando e direcionando a prática espacial, explicitamente, nos limites impostos à apropriação do tempo e do espaço. Isto porque a reprodução do espaço repõe, constantemente, a dialética entre apropriação/propriedade privada justificada pelos poderes jurídicos através do papel disciplinador do Estado (construção de instrumentos de controle do espaço e de direcionamento dos investimentos). Por sua vez a ação do capital em direção à acumulação, como processo de valorização constante sobre a base reprodutiva da sociedade, produz novas representações, induzindo a universalização dos valores de consumo, a desterritorialização da cultura, com a crescente eficácia das mídias. Com isso celebra-se o presente como consumo do espetáculo constante, enquanto a vida se realiza como reino da passividade quase absoluta. A reprodução ancorada em valores de consumo universais, valores morais ancorados no mundo do dinheiro e da produção de imagens a ele associada, cria a falência dos referenciais que sustentam a vida urbana, posto que constituidores da identidade. Com isto, a explosão dos lugares da vida, a transformação dos hábitos que embasam a sociedade e um modo de vida urbano que se estabelece sustentado por uma nova ordem que penetra concretamente a prática sócio-espacial, construindo uma "identidade abstrata" (CARLOS, 2001) que amálgama a sociedade moderna gerando novas formas de conflito. Esse movimento aponta a necessidade da compreensão da esfera do cotidiano como um espaço e um tempo subsumidos à lógica da acumulação sob a égide do Estado. Sua análise também revela as lutas pelo e em torno do espaço como lugar/produção da vida humana. Isto porque, a contradição que funda e explicita a reprodução do espaço urbano (a produção social em confronto com sua apropriação privada) desdobra-se no mundo moderno, como a vitória do valor de troca em relação ao valor de uso realizando-se na prática sócio-espacial como negação da apropriação. O domínio do valor de troca - como condição da existência e extensão da propriedade privada e das relações capitalistas de produção - esvazia o uso produzindo a cidade como fragmentação de lugares e momentos da vida urbana que aprofunda a desigualdade encontrando seu limite na exacerbada concentração da riqueza. A análise do cotidiano, todavia, ilumina duas situações em conflito que permeiam e fundam a prática sócio-espacial (que contém um tempo vivido): as formas de alienações vividas e o devir que orienta o pensamento e um projeto de sociedade.

O urbano como realidade tem materialidade na cidade. Mas se é possível reconhecer, como faz Lefebvre (1953), que para cada forma artística corresponde um sentido humano, a 
pintura e a escultura para o olho, a música para o ouvido, ainda podemos acrescentar a culinária para o gosto, a cidade, enquanto prático-sensível, neste raciocínio, pode ser relacionada ao corpo, mas enquanto tal, ele inclui todos os sentidos humanos. Assim, a cidade analisada como obra de arte é produzida para corpo - vivida pelo homem através de todos os seus sentidos. Todavia a cidade como obra de arte não é a produção de um só indivíduo, senão do conjunto da sociedade o que dispõe um indivíduo em relação ao outro da relação. Com isso, a cidade é obra de todos para cada um - é a história particular realizando-se como história coletiva. Esse é o raciocínio que orienta o entendimento da cidade como criação, como objeto rico de sentido e nesta condição, a cidade é possibilidade capaz de liberar o ser humano de seus limites(CARLOS, 2005, p. 226).

O conteúdo da urbanização desvenda-se, assim, a partir das dimensões espaciais deste processo. Como toda atividade de conhecimento, o pesquisador situa-se num lugar, o desenvolvimento da disciplina tem com o ponto de partida e chegada a metrópole de São Paulo o que implica pensar a metrópole como especificidade - lugar de onde é possível construir uma compreensão sobre nossa sociedade - que se apresenta, hoje, como sociedade urbana. Todavia, uma questão se estabelece: pensar o mundo e nossa condição no mundo a partir da cidade e, particularmente da metrópole, é a garantia necessária a partir da qual se poderia ler o mundo contemporâneo?

\section{Sobre os conteúdos}

A noção de "produção do espaço" coloca-se no centro do debate e orienta a reflexão, trazendo novas exigências teóricas. A interpretação materialista do espaço - e consequentemente do tempo - focando a espacialidade das relações sociais permite, como já adiantamos, superar as análises que veem no espaço a localização das atividades humanas permitindo pensar a produção do espaço encontrando o sujeito produtor em suas condições históricas determinadas. Isso significa, do ponto de vista da Geografia, a indissociabilidade entre produção do espaço e produção da vida (a produção no sentido amplo - produção por ela mesma do ser humano - implica e corresponde aquela das ideias, das representações, da linguagem) exprimindo o fato de que os homens só realizam sua vida através da apropriação-uso dos lugares sem os quais a vida não se realiza, o que envolve o corpo e todos os seus sentidos. Já a cidade como conceito e realidade concreta realiza-se numa 
miríade de espaços-tempos justapostos; os da troca, do lazer, da circulação, do trabalho, reunindo e centralizando todos os elementos que dão sentido à vida social. Nesta direção o desvendamento da cidade aponta a compreensão do urbano no contexto da constituição da humanidade do homem. Assim, pensar a cidade e o urbano é pensar a vida do homem, seus desejos e necessidades, como determinada sociedade vive e se reproduz na cidade e como pensa o seu futuro e aquele da cidade. Deste modo a questão espacial se coloca no plano da construção do humano na medida em que o ato de produção do espaço é, em si mesmo, produção da vida. A análise urbana, ao revelar a reprodução da vida em todos os seus sentidos, revela momentos de alienação - desalienação, passividade e luta. Esta é a tese que fundamenta a construção das hipóteses que, em seu conjunto, denotam a totalidade do fenômeno urbano, permitindo sua compreensão.

Primeira hipótese: A Geografia se abre para a construção da compreensão do mundo através da espacialidade das relações sociais. Nessa perspectiva podemos entender as relações sociais materializando-se na condição de relações espaciais (com significados diferenciados em função do momento histórico) permitindo situar o pensamento na práxis como prática sócio-espacial. A produção do espaço é um momento necessário da produção da vida, na medida em que a existência dos homens depende de uma condição material inicialmente seu corpo em relação com a natureza e posteriormente, criando um segunda natureza como condição da re-produção da vida. Este faz-se como desdobramento do processo de produção apoiado em novas técnicas que desenvolvem as forças produtivas, permitindo um distanciamento cada vez maior da natureza em direção à construção de um mundo social - a cidade como trabalho materializado. Deste modo a compreensão da cidade e do urbano ilumina a vida urbana - o tema portanto, ao mesmo tempo em que é analisado pela Geografia escapa a ela tanto no plano da totalidade do fenômeno quanto no âmbito das ciências humanas. Deste modo esse encaminhamento não objetiva justificar uma Geografia, mas discernir/refletir sobre a realidade urbana como possibilidade contida na espacialidade das relações sociais.

Tal procedimento supera um pecado original da análise geográfica: a ilusão criada de uma transparência do espaço que em sua materialidade se esgotaria numa objetividade absoluta - o quadro físico e sua representação no mapa - encobrindo os conteúdos sociais.

Segunda hipótese: Ao longo do tempo histórico um processo ininterrupto de produção ilumina a constituição da cidade e do urbano. Deste modo, a cidade se revela como obra da 
história humana constituindo-se em cada momento com particularidades específicas (em sua determinações históricas), revelando os conteúdos do mundo em seu movimento e tendências. Portanto o movimento interno da produção do espaço encontra finalidade na constituição do "social". Expressão e significação da vida humana, a cidade é obra, constituída ao longo do processo histórico cumulativo, neste sentido contém e revela ações passadas ao mesmo tempo que o futuro se constrói nas tramas do presente, através das tendências que contempla uma multiplicidade de formas, temporalidades diferenciadas. Aqui o método progressivo-regressivo permite encontrar na história dos modos de produção uma história da cidade, como periodização possível - como continuidade/descontinuidade em seus pontos de ruptura. A longa duração diz respeito ao processo de gênese da cidade, mas o retorno à história da cidade objetiva buscar aquilo que a funda: a hierarquização da sociedade em classes, a divisão do trabalho, o exercício do poder, suas representações.

Terceira hipótese: 0 processo de acumulação que na hipótese anterior aparecia como pressuposto da construção do mundo que explicita o capitalismo, aqui se revela como produto da história. O movimento que vai da história do processo de produção da cidade àquele da metrópole revela o momento da generalização do urbano que se situa no processo geral de industrialização que ao se reproduzir ultrapassa seus limites iniciais estendendo-se desmesuradamente no espaço e penetrando profundamente a vida cotidiana, transformando-a. A metrópole como força produtiva do capital é o momento negativo : é a negação da cidade e da vida cotidiana na cidade. Portanto sua constituição revela uma transformação necessária da reprodução das condições gerais do capitalismo como processo de acumulação ampliada. Sua existência aponta a disposição diferenciada de lugares como condição geral no âmbito da reprodução do capital envolvendo as relações sociais. Estes aparecem no âmbito da lógica do espaço como integração-desintegraçãohierarquização dos lugares.

O desenvolvimento da industrialização tem um sentido quantitativo - a produção cada vez mais ampliada de produtos e relações sociais (e de propriedade) que a sustentam - e qualitativo - produção do mundo da mercadoria como realidade urbana ampliada, como sentido de uma sociedade que caminha em direção à constituição do urbano: uma ordem em que predomina o valor de troca sobre o valor de uso, contraditoriamente. No processo é o próprio espaço que se transforma em mercadoria - apesar de diferente das outras mercadorias, posto que contempla sua própria negação. 
Quarta hipótese: A reprodução do espaço urbano, sob o capitalismo, aponta a vitória do valor de troca sobre o valor de uso. A extensão do mundo da mercadoria tomou o espaço, produzindo-o como mercadoria. Trata-se de uma relação social que pela dupla determinação do trabalho (satisfazer uma necessidade e gerar mais valor) cria a contradição valor de uso/ valor de troca. A produção do espaço enquanto mercadoria faz do acesso ao uso uma relação necessariamente mediada pelo mercado imobiliário, o qual é coordenado pela lógica de ações políticas e pelo controle sobre a técnica e do saber (assentadas em relações de dominação-subordinação/uso-apropriação). Do ponto de vista da acumulação, a metrópole surge como localização e suporte das relações sociais de produção (e de propriedade) condição e meio da realização concreta do ciclo reprodutivo do capital, recriando, constantemente, os lugares propícios de realização dos momentos de produção, distribuição, circulação, troca e consumo de mercadorias - tanto materiais quanto imateriais, como possibilidade sempre ampliada de realização do capital. Por outro lado, o espaço urbano, na condição de mercadoria, entra no circuito de valorização e todos os lugares se submetem a esta lógica.

Quinta hipótese: O capitalismo cria incessantemente suas próprias condições de reprodução. O momento atual é aquele da ampliação do mercado mundial do processo de reprodução capitalista, da redefinição das centralidades, envolvendo todo o espaço. Abre-se, assim duas dimensões; a) mundialidade como constituição do espaço mundial com a manifestação de novas contradições e o aprofundamento entre os espaços integradosdesintegrados ao capitalismo globalizado, sob a égide do estado redefinindo a relação deste com a economia e com o espaço, b) as transformações no nível do local, vividas nas práticas da vida cotidiana. A mundialização traz um conteúdo social ao processo econômico, colocando-nos diante da constituição tendencial de um espaço mundial e de uma sociedade urbana. Novas relações espaço-tempo, como momento da reprodução da vida na cidade, apontam a construção de um tempo efêmero e de um espaço amnésico. Neste processo a metrópole se constitui como importante mediação entre o local e o mundial.

No plano do lugar, a generalização da urbanização e da formação de uma sociedade urbana impõe os padrões de comportamento, o modo de vida, os valores, obedecendo a uma racionalidade inerente ao processo de reprodução das relações sociais. A produção do espaço como momento da vida faz parte do conjunto das produções que permitem sua realização constante num determinado lugar e tempo definidos (aquela da proximidade, 
mas unindo e justapondo escalas) interligando-se dialeticamente à escala do mundial, que se anuncia hoje com a expansão do capitalismo.

Uma tendência à homogeneização, caminha, progressivamente, ao lado de um processo de fragmentação do espaço e da sociedade posto que, a acumulação produz uma racionalidade homogeneizante inerente ao processo, que não se realiza apenas produzindo objetos/mercadorias mas, ligando-se cada vez mais, à produção do espaço-mercadoria que se realiza pela fragmentação de parcelas do espaço compradas e vendidas no mercado imobiliário. Neste movimento subjugou o uso, como condição de realização da vida social, às necessidades da reprodução econômica, como imposição da acumulação. É nesse processo que o valor de troca ganha uma amplitude profunda. 0 limite deste processo pode ser constatado pela produção dos simulacros espaciais proporcionados, seja pelas exigências do desenvolvimento do turismo, seja como decorrência de revitalizações urbanas.

Sexta hipótese: O cotidiano se constitui como produto da história; isto é, como consequência do processo de reprodução da sociedade envolvendo uma relação espaçotempo. Como categoria de análise, o cotidiano, desloca o enfoque do processo de reprodução do plano econômico para o plano social - a reprodução das relações sociais determinadas num outro patamar. Nesta dimensão o cotidiano constitui-se como produto da história. Ele, portanto explica: a) a vida cotidiana em suas relações espaço-temporais e em sua completa subsunção às necessidades do desenvolvimento do processo de reprodução econômica; b) as novas relações entre as esferas do econômico e do político, dando um novo sentido para o Estado que vai reproduzir-se através da produção estratégica do espaço; c) o valor de troca invadindo o espaço, subjugando a vida e os conteúdos da prática espacial e explicitando as lutas em torno da moradia e dos acessos ao urbano.

Este é o momento em que, no plano do econômico, o desenvolvimento do mundo da mercadoria cria, desenvolve e aprofunda a sociedade do consumo, a qual reduz o cidadão à passividade crescente redefinindo as relações entre as pessoas, reorientando as energias e os "sonhos" pela profusão de produtos e serviço sofisticados e sempre atualizados, implodindo as relações tradicionais, forjando um novo tipo de identidade baseada na indiferença em relação ao outro. A atomização das relações, permite vislumbrar a emergência do que Horkheimer chamou de um novo "ser no mundo" (um novo individualismo marcado pela imposição do reino do objeto sobre um indivíduo manipulado e programado). 
Sétima hipótese: As condições de estabilidade do capitalismo e sua manutenção exigem a acumulação ampliada. Na metrópole esse processo se realiza em sua plenitude sinalizando um presente contraditório - crítico - e um futuro em construção. O que está em jogo é um novo momento da história da sociedade capitalista que muda radicalmente a vida e as formas de sua apreensão pelo cidadão envolto na instauração do cotidiano. O novo no processo aponta um movimento de passagem da hegemonia do capital industrial ao capital financeiro - no movimento do processo de mundialização - no contexto geral que objetiva a realização do valor. Se a expansão do mundo da mercadoria produziu o espaço urbano como mercadoria, num primeiro momento, em seguida a própria cidade se torna mercadoria. Desse modo os processos se aceleram.

A metrópole se transforma com uma velocidade incrivelmente grande - o que antes demorava décadas, de repente, se transforma em poucos anos. O mundo contemporâneo se reproduz através de estratégias e manipulações do capital financeiro cada vez mais desterritorializado. A produção dos novos e imensos edifícios multifuncionais tornam a cidade obsoleta. Explodida, a cidade revela-se segregada pelo desenvolvimento da propriedade privada da riqueza que associa concentração de renda (acesso ao emprego/ingresso ao mercado/ acesso aos lugares privilegiados da cidade) aos usos do espaço urbano. O Estado, através do planejamento, reproduz um espaço de dominação, homogêneo que ora entra em contradição/conflito com o espaço dos interesses específicos da reprodução do capital, ora se alia a ele.

A cidade do século XXI expressa a segregação como forma da desigualdade social. Segregação não como separação entre grupos no espaço urbano descontínuo, mas como produto do movimento de realização da propriedade privada da riqueza que na produção do espaço urbano revela-se através da propriedade privada do solo urbano. Tal situação cria confrontos que se desdobram na luta pelo direito à cidade.

Oitava hipótese: A cidade como negócio. Podemos distinguir dois momentos importantes do processo de urbanização da metrópole de São Paulo; a urbanização imediatamente, decorrente do processo de industrialização - processo marcado pela acumulação do capital industrial, a partir da acumulação proveniente da agricultura cafeeira criando as grandes periferias, com a implosão da cidade - e o momento em que o processo de urbanização tem por conteúdo a realização do capital financeiro. O que há de novo neste processo é que o 
setor financeiro vai se realizar através do espaço, isto é, produzindo o espaço. O capital tende a migrar de um setor ao outro da economia e quando isto ocorre, uma nova infraestrutura se torna necessária como condição e meio para que este processo se realize. Isso significa dizer que a centralização financeira vai apontar um fenômeno importante: o capital financeiro se realiza, hoje, através da produção do espaço como exigência da acumulação continuada do capital, sob novas modalidades articuladas ao plano do mundial, constituindo, em São Paulo um eixo financeiro empresarial que se estende desde o centro da metrópole em direção ao sudoeste, ocupando áreas antigas de industrialização. A reprodução do espaço urbano da metrópole sinaliza, portanto, o momento em que o capital financeiro se realiza também através da produção de "um novo espaço" sob a forma de "produto imobiliário" voltado ao mercado de locação, (fundamentalmente no que se refere aos edifícios corporativos de escritórios, rede hoteleira e flats) numa estratégia que associa várias frações do capital a partir do atendimento do setor de serviços modernos. Neste sentido, estabelece-se um movimento de passagem da predominância/presença do capital industrial produtor de mercadorias destinada ao consumo individual (ou produtivo) à preponderância do capital financeiro que produz o espaço como mercadoria enquanto condição de sua realização.

Nona hipótese: A produção da cidade como exterioridade, percebida como estranhamento, atualiza a forma da alienação no mundo moderno. A normatização das relações sociais, a rarefação dos lugares de encontros, a deterioração do espaços públicos, a retração da esfera pública, tudo isso se estabelece como mal-estar, como estranhamento. A instauração do cotidiano como atomização, ao mesmo tempo que superorganização da vida, impõe-se sem resistência, delineando uma nova urbanidade. Campo da autorregulação voluntária e planificada, o cotidiano aparece como construção da sociedade, que se organiza segundo uma ordem fortemente burocratizada; preenchido por repressões e coações imperceptíveis. Esse processo que se realiza no lugar, revela articulações espaciais mais amplas. A possibilidade criativa está reduzida, confinada; a cidade se opõe ao indivíduo enquanto objeto estranho; como potência independente; a alienação se estende por toda a vida do habitante.

A contradição entre o processo de produção social do espaço e sua apropriação privada marca e delimita a vida cotidiana A prática ganha sentido na reprodução das relações sociais, onde se defrontam as estratégias da reprodução das frações de capital e da realização da 
vida social significativamente. No processo há degradação de formas e relações sociais antigas frente ao estabelecimento de novas relações num movimento de preservaçãodegradação-transformação, enquanto característica do processo de reprodução das relações sociais, hoje. Portanto a prática espacial vai revelar a extrema dissociação dos elementos da vida como separação dos espaços-tempos da vida cotidiana - separando o lugar de moradia do lugar do trabalho, criando espaços precípuos para o lazer (geralmente com acesso pago, direta ou indiretamente - esvaziando a rua, e deteriorando os espaços públicos), criando dificuldades de locomoção (CARLOS, 2009).

No plano do vivido (espaço e tempo do vivido) aparecem entrecortados, fragmentados por atividades divididas e circunscritas, em que o habitar enquanto ato social vai desaparecendo à medida que a habitação se reduz a abrigo. Portanto, no espaço concretiza-se a justaposição entre morfologia social e morfologia espacial que define o acesso e lugar de cada um no espaço, revelando uma hierarquia social enquanto prática sócio-espacial. Isso significa dizer que se a realização do capitalismo hoje produziu o espaço como sua condição de reprodução. Nessa condição, produziu um espaço fundado na contradição entre os espaços integrados ao capitalismo globalizado através do capital financeiro e os espaços das imensas periferias onde a privação do trabalho, da alimentação, da moradia, de uma vida digna, é a tônica dominante. Mas desta situação emerge aquilo que a nega. Está posta na vida cotidiana a possibilidade de através da insurgência (pela constituição da consciência da prática sócio-espacial) do enfrentamento contra o empobrecimento da vida em todos os sentidos. Assim a prática sócio-espacial enquanto realização das necessidades da vida cotidiana e da manutenção da vida uma ação se contrapõe à reprodução que escapa ao plano da sociedade. Os movimentos sociais revelam o conteúdo de exigências diferenciadas; tanto a urgência da moradia, do emprego e dos serviços, quanto através do questionamento das políticas públicas, questionando o planejamento estatal que aprofunda, as desigualdades. Esses movimentos, no seio da sociedade, apontam a instabilidade, se defrontam com a propriedade na prática sócio-espacial vivida visando a apropriação não apenas como o outro da propriedade, mas como possibilidade poiética - o humano como criação prática e a prática enquanto realização do humano. Neste momento o projeto de uma outra sociedade surge como dialética necessidade/desejo que pressupõe a consciência daquilo que impede que a vida de realiza em sua plenitude. 
Décima hipótese: $\mathrm{O}$ direto à cidade como horizonte para a construção de um projeto de sociedade. O pensamento de Marx ao manter a unidade do real e do conhecimento, da natureza e do homem, do presente e do futuro, explora uma totalidade em devir. No mundo moderno este pensamento permite atualizar a utopia. Os movimentos sociais na cidade surgem como manifestação contrária à vida cotidiana normatizada e esvaziada do sentido da vida; impõem a construção de um espaço que negue o habitat produzido sob a racionalidade da reprodução político-econômica no "habitar como realização da vida" que transcende o plano específico da moradia, reunindo os elementos que sustentam a cidadania. $\mathrm{O}$ ato de morar é o ato de habitar, que não se restringe ao espaço do privado, mas envolve as relações com os espaços públicos como os lugares da realização da sociabilidade, dos encontros, da esfera pública, portanto do debate, da criação e da festa. Assim, o indivíduo se coloca no espaço na relação com o outro, e é nesse sentido que a prática sócio-espacial revela o uso, como expressão poética - que aponta a cidade como obra.

\section{Um exercício de método}

A crítica, como atitude, envolve captar as possibilidades existentes num mundo em transformação, em sua complexidade como totalidade realizando-se, hoje, como mundialidade, ultrapassando a mera constatação das coisas. Isto exige a crítica da Geografia, abrindo o caminho teórico necessário para elucidar a dialética do mundo. Com isso a necessidade de superar a aparente transparência do espaço que produziu várias simplificações como uma disciplina restrita ao mundo fenomênico, apoiada na constatação de um espaço imediatamente objetivo em sua materialidade absoluta, e orientada pela descrição. Portanto a compreensão envolve a exigência de um momento crítico - como aquele da interrogação, da busca da totalidade como necessidade de superação das fragmentações às quais o pensamento ou a Geografia estão submetidos, através da busca de categorias universais de análise.

"Da noção de organização àquela de produção do espaço" os geógrafos percorreram um longo caminho. Neste processo a obra de Marx foi fundamental para iluminar a noção de produção em seu desdobramento (a reprodução) no plano da realidade prática e no âmbito da filosofia. Nesse processo, o materialismo dialético, como caminho da pesquisa capaz de 
orientar o entendimento da realidade, permitiu pensar o espaço como mercadoria. Nesta condição, permitiu a construção do entendimento do espaço capitalista como produção social alienada através de sua constituição enquanto mercadoria.

A reprodução tem o sentido da constante produção das relações sociais estabelecidas a partir de práticas espaciais enquanto acumulação, preservação, renovação. A reprodução do espaço urbano é um fenômeno contínuo, em movimento, o que significa que a cidade vai se transformando à medida, que a sociedade vai se metamorfoseando - transformações que se estabelecem no plano do vivido, determinando padrões, concretizando a ordem distante, na ordem próxima. Os problemas postos pela urbanização ocorrem no âmbito do processo de reprodução geral da sociedade, manifestando-se, concretamente, no plano da vida cotidiana. A noção de cotidiano, por sua vez, permitiu o deslocamento da análise do plano do econômico àquele do social, iluminando as contradições vividas, Ele se liga à noção de reprodução (a um momento histórico deste processo) que compreende uma multiplicidade de aspectos, sentidos, valores. Torna-se, assim, indissociável as relações entre a reprodução do espaço e a reprodução da vida na metrópole a partir da análise da vida cotidiana - lugar onde se constata a tendência desigual e contraditória da instauração do cotidiano.

A análise do urbano engloba, portanto, um universo complexo de relações em constituição da qual não se exclui a ideia de projeto capaz de realizar o "direito à cidade" com a participação de todos no controle e gestão da cidade. O processo de transformação da sociedade passa pela construção de uma teoria radical, capaz de rasgar o véu ideológico revelando o conteúdo dessa sociedade capitalista através da explicitação de suas contradições, e dos projetos que estão na ordem do dia desta sociedade. É nesse sentido que a dialética revela sua negatividade e a contradição ganha importância central. A produção do espaço no centro da análise implica um sentido da noção de produção que muda os termos do problema em tela enquanto, no mundo moderno, a produção da cidade, revela uma problemática de ordem espacial.

Sintetizando, a análise enfoca o movimento do pensamento que vai na direção do concreto, para considerar a prática urbana envolvendo a sociedade em seu conjunto, em sua ação real - em seu conteúdo social - objetivando-se. Assim, as relações sociais se materializam concretamente na cidade enquanto relações espaciais. Tal afirmação supera o entendimento da cidade como quadro físico, aglomerado de homens e coisas, abrindo a perspectiva de entendê-la em sua pluralidade de sentidos - usos possíveis, enquanto lugares de 
convivência, de reunião, de sociabilidades, lugares, nos quais se desenvolve a vida confrontada com as transformações; em suas persistências e rupturas; ao mesmo tempo em que esperança e desejo.Deste modo nos confrontamos com a realidade em sua dinâmica contraditória. Sem negar a ideia de centralidade como conteúdo da noção de cidade, é de fundamental importância considerar três dimensões espaço-temporais: a) em sua dimensão histórica,a cidade é obra da civilização e nesta condição, produto realizado ao longo de uma série de gerações (portanto trabalho materializado) e, neste plano, aparece como acumulação de tempos; b) lugar enquanto prática social, a cidade é espaço-tempo da ação que funda a vida humana em sua objetividade não limitada a um simples campo de experiência. Nesta condição, a cidade é, por excelência o lugar da apropriação da vida, através do corpo e de todos os sentidos, que para Lefebvre são as determinações do ser humano; c) devemos pensá-la como virtualidade, possibilidade futura de realização da vida neste plano ela aponta a universalidade do humano.

\section{REFERÊNCIAS BIBLIOGRÁFICAS}

BOTELHO, Adriano. A produção do espaço como estratégia do capital. In: $\mathbf{O}$ urbano em fragmentos. São Paulo: Annablume, 2009. p. 00-00.

CARLOS, Ana Fani Alessandri. A cidade. São Paulo: Editora Contexto, 2011.

O direto à cidade e a construção da meta-geografia. Revista Cidades, Presidente Prudente, v. 2, n. 4, p. 221-248, 2005.

O espaço urbano: novos escritos sobre a cidade. São Paulo: FFLCH/USP, 2011. Disponível em: <www.gesp.fflch.usp.br>. Acesso em: 10 out. 2012.

Uma leitura sobre a cidade. Revista Cidades, Presidente Prudente, v. 1, n. 1, p. 11-30, 2004.

o lugar no/do mundo. São Paulo: FFLCH/USP, 2011. Disponível em: <www.gesp.fflch.usp.br>. Acesso em: 10 out. 2012.

A metrópole de São Paulo no contexto da Urbanização Contemporânea. Revista de Estudos Avançados, São Paulo, v. 23, n. 66, 2009. 
A (re)produção do espaço urbano. 2ạ. ed. São Paulo: EDUSP, 2008.

CARLOS, Ana Fani Alessandri; CARRERAS, Carles. Urbanização e mundialização: estudos sobre a metrópole. In: Urbanização e Mundialização. São Paulo: Contexto, 2005. p. 29-37.

CARLOS, Ana Fani Alessandri; DAMIANI, Amélia Luisa e SEABRA, Odette Carvalho de Lima. 0 espaço no fim de século: a nova raridade. São Paulo: Contexto, 1999.

CARLOS, Ana Fani Alessandri; SOUZA, Marcelo Lopes de; SPOSITO, Maria Encarnação. A produção do espaço urbano: agentes e processos, escalas e desafios. São Paulo: Editora Contexto, 2011.

CORRÊA, Roberto Lobato. O espaço urbano. São Paulo: Editora Ática, 1989.

Rede urbana e formação espacial: uma reflexão considerando o Brasil. Revista Território, Rio de Janeiro, n. 8; jan./jun. 2000.

COULANGES, Fustel. A cidade antiga. São Paulo: Martin Claret, 2003.

DAMIANI, Amélia Luisa. A Urbanização crítica na metrópole de São Paulo a partir de fundamentos da geografia urbana. Anais do 12. Encuentro de Geógrafos de América Latina. Montevidéu: EGAL, 2009.

EMPLASA. Reconstrução da memória estatística da Grande São Paulo. São Paulo: Secretaria dos Negócios Metropolitanos,1980.

GEORGE, Pierre. Geografia urbana. São Paulo: DIFEL, 1983.

GESP. Grupo de geografia urbana critica radical. Edições FFLCH/USP. Disponível em: $<w w w . g e s p . f f l c h . u s p . b r>$ (Editora eletrônica de acesso gratuito).

HARVEY, David. Condição pós-moderna. São Paulo: Ed Loyola, 1992

A produção capitalista do espaço. São Paulo: Annablume, 2005.

IANNI, Otávio. Sociedade global. Rio de Janeiro: Civilização Brasileira, 1992.

LEFEBVRE, Henri. El derecho a la ciudad. 4ạ. ed. Barcelona: Península, 1978. 
. Espaço e Política. Belo Horizonte: Editora UFMG, 2008.

. Introduction à l'esthètique. Paris: Éditions Sociales, 1953

MATOS, Olgária. A cidade e o tempo. Revista Espaço e Debate, São Paulo, n. 7, p. 7-15, 1983.

MONBEIG, Pierre. O estudo geográfico das cidades. Boletim geográfico, Rio de Janeiro, out. 1943.

MUMFORD, Lewis, A cidade na história. Belo Horizonte: Editora Itatiaia, 1965, 2 vol.

PACQUOT, Thierry, Homo urbanus. Paris: Essai Éditions du Félin, 1990.

REVISTA CIDADES. Presidente Prudente: GEU, 2004/2012.

RIBEIRO, Luiz. César de Queiroz. (org). Metrópoles. São Paulo; Rio de Janeiro: Fundação Perseu Abramo; Observatório das metrópoles; FASE, 2004.

SALGUEIRO, Teresa Barata. Globalização e reestruturação urbana. Lisboa: Centro de Estudos de Lisboa, 1998. Série Monografia.

SANTOS, Milton. O espaço dividido: os dois circuitos da economia urbana dos países subdesenvolvidos. 2a. ed. Rio de Janeiro: Francisco Alves, 2004.

. Manual de geografia urbana. São Paulo: EDUSP, 2008.

SANTOS, César Simoni . Negócios da cidade à cidade como negócio: uma nova sorte de acumulação primitiva do espaço. Revista Cidades, Presidente Prudente, GEU, n.ำ 7, 2009.

SASSEN, Saskia. A cidade global. In: LAVINAS, Lena et alii (org). Reestruturação do espaço urbano e regional no Brasil. São Paulo: ANPUR/ Hucitec, 1993.

SEABRA, Odete. Os territórios do uso: cotidiano e modo de vida. Revista Cidades, n.ㅇ 2, 2004, p. 181-206.

SILVA, José Borzachiello. (org) A cidade e o urbano: temas para o debate. Fortaleza: EDUFC, 1997. 
SINGER, Paul. Economia política da urbanização. São Paulo: CEBRAP; Editora Brasiliense, 1973.

SMITH, Neil. Gentrificação: a fronteira e a reestruturação do espaço urbano. IN: GEOUSP, São Paulo, n.ㅇ 21, 2007.

SOJA, Edward. Geografias pós-modernas: A reafirmação do espaço na teoria social crítica. Rio de Janeiro: Jorge Zahar, 1993.

SOUZA, Maria Adélia et alii (orgs.). Metrópole e globalização. São Paulo: CEDESP, 1999.

SPOSITO, Maria Encarnação Beltrão. Cidades médias: espaços em transição. São Paulo: Expressão Popular, 2007.

- (org.) Urbanização e cidades: perspectivas geográficas. Presidente Prudente: GAsPERR/ UNESP, 2001.

VASCONCELOS, Pedro. Dois séculos de pensamento sobre a cidade. Ilhéus: Editora Editus, 1999.

et alii. Novos estudos de geografia urbana brasileira. Salvador: Editora da Universidade Federal da Bahia, 1999. 